\title{
One-lung ventilation with use of a double lumen tube in two dogs; when right might be wrong
}

\author{
Donna Maree White*, Alastair R. Mair and Fernando Martinez-Taboada \\ Department of Anaesthesia, University of Sydney, Veterinary Teaching Hospital, Evelyn Williams Building B10, \\ 65 Parramatta Road, Camperdown, NSW. 2050, Australia
}

\begin{abstract}
One-lung ventilation (OLV) is an anaesthetic technique utilised for improved visualisation and access of the surgical field during thoracoscopy. The authors present two cases that underwent OLV with use of a double lumen tube (DLT). The first case was intubated with endoscopic guidance for bronchial port intubation of the right mainstem bronchus. This dog experienced prolonged periods of intraoperative hypoxemia. Upon case review, it was suspected intubation of the mainstem bronchus resulted in occlusion of the right cranial lung lobe. In the second case, the DLT was placed bronchoscopically into the left mainstem bronchus with the aid of computed tomography (CT). Excellent intraoperative oxygenation was achieved. When DLTs are used in dogs, their anatomical differences from humans make them susceptible to additional lung occlusion and pulmonary shunting. Computed tomography is recommended as a fundamental addition to bronchoscopy for correct tube placement.
\end{abstract}

Keywords: Anaesthesia, Double lumen tube, One-lung ventilation, Thoracoscopy.

\section{Introduction}

Thoracoscopy is an increasingly performed surgical method in veterinary medicine (Fransson, 2015). It offers a minimally invasive approach with faster recoveries, reduced post-operative pain and morbidity, and consequently shorter hospital stay (Walsh et al., 1999; Flores et al., 2009; Stankowski et al., 2017). Thoracoscopy is ideally performed with the aid of onelung ventilation (OLV) anaesthesia. This allows the selective ventilation of one lung with iatrogenic collapse of the contralateral lung to improve visualisation and access of the surgical field. As a consequence, OLV induces substantial ventilation perfusion mismatching with a significant risk of hypoxemia (Karzai and Schwarzkopf, 2009).

There are three techniques that can be used to perform OLV including selective intubation of a mainstem bronchus (endobronchial intubation), use of a doublelumen tube (DLT) (Mayhew and Friedberg, 2008; Adami et al., 2011) or use of a bronchial blocker (Cantwell et al., 2000; Lansdowne et al., 2005). Double lumen tubes consist of two tubes of different lengths connected longitudinally together (Fig. 1).

The longer tube provides intubation of a mainstem bronchus while the shorter tube is positioned so that the distal end is within the trachea (Fig. 2).

Lung ventilation can be performed through either tube, for OLV, or alternatively, through both tubes simultaneously to provide two-lung ventilation (TLV), as indicated during a procedure.

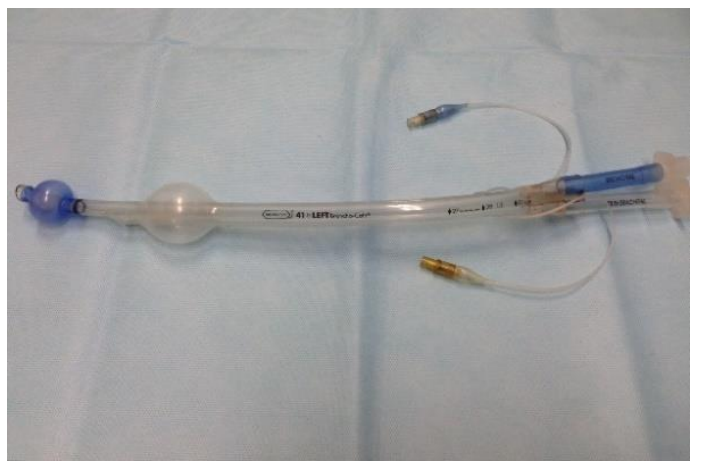

Fig. 1. Left-sided double-lumen tube, as used in both Case 1 and 2. Tracheal port and cuff are clear, bronchial port and cuff are blue.

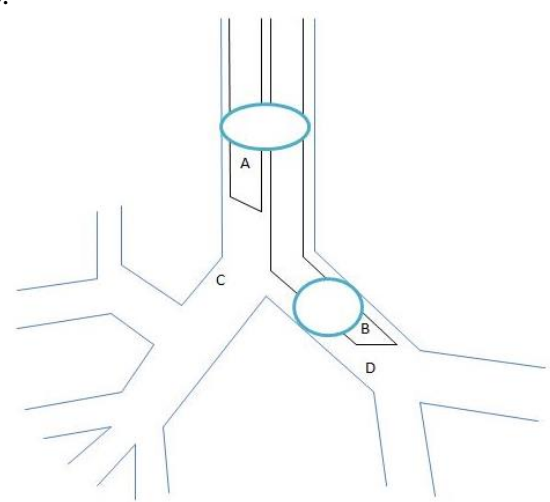

Fig. 2. Diagram showing correct placement of double-lumen tube with bronchial port in left mainstem bronchus. (A): tracheal tube; (B): bronchial tube; (C): right mainstem bronchus; (D): left mainstem bronchus. 
Double lumen tubes are designed for human use and the significant human-canine pulmonary anatomical differences must be considered when adapting a DLT for use in a dog.

The canine compared to human trachea is proportionally longer, while the mainstem bronchi are shorter (Pascoe and Mayhew, 2015). In dogs, DLT placement may produce some degree of maintstem, and, or, cranial to mid-lung lobe bronchus occlusion. To avoid these potential complications, it is currently recommended that DLT be placed via bronchoscopy (Wiser, 2012; Mosley, 2015; Pascoe and Mayhew, 2015).

\section{Case 1}

\section{Case Details}

A 14-year-old female neutered Australian Cattle Dog underwent thoracoscopic removal of a left cranial pulmonary mass. The mass had been identified incidentally four months previously during a preoperative CT for left laryngeal lateralisation surgery. The owner reported the dog had recently developed a cough but was otherwise well. Preoperative physical examination showed increased upper respiratory tract sounds with normal respiratory pattern, as expected following laryngeal lateralisation surgery, and was otherwise normal. Preoperative blood testing (PCV/TP/electrolytes) was unremarkable.

\section{Case 2}

A 10-year-old male neutered German Shepherd underwent thoracoscopic removal of a right caudal pulmonary mass. The dog had a two-month history of coughing with haemoptysis. Preoperative physical examination was unremarkable. Preoperative blood testing (PCV/TP/electrolytes) was unremarkable.

\section{Procedures}

\section{Case 1}

The dog was fasted for 10 hours prior to intramuscular sedation with $0.02 \mathrm{mg} / \mathrm{kg}$ acepromazine (A.C.P.2, Delvet, Australia) and $0.3 \mathrm{mg} / \mathrm{kg}$ methadone (Ilium Methadone, Troy Laboratories Pty Ltd, Australia). Thirty-five minutes following premedication oxygen (4 $\mathrm{L} / \mathrm{min}$ ) was administered for five minutes via a facemask. Anaesthesia was induced with a combination of $5 \mathrm{mg} / \mathrm{kg}$ ketamine (Ceva Ketamine, Ceva Animal Health Pty Ltd, Australia) and $0.25 \mathrm{mg} / \mathrm{kg}$ midazolam (Midazolam Alphapharm, Alphapharm Pty Ltd, Australia) administered intravenously. The dog's trachea was intubated with a $10 \mathrm{~mm}$ internal diameter cuffed endotracheal tube (ETT) (Portex 10.0 Oral/Nasal Endotracheal tube; Smiths Medical Australasia, Australia). The ETT was connected to a circle breathing system and anaesthesia was maintained with isoflurane (Isothesia, Henry Schein, Australia) in oxygen (2 L/min). Fentanyl (10-15 ug/kg/hr) (DBL Fentanyl Injection, Hospira Australia Pty Ltd, Australia) and ketamine (5-10 ug/ $\mathrm{kg} / \mathrm{min}$ ) infusions were started adjusting the rates as indicated by plane of anaesthesia and response to surgery.

Continuous monitoring of vital parameters (heart rate, arterial haemoglobin saturation, end tidal carbon dioxide, respiratory rate, non-invasive and invasive blood pressure and oesophageal temperature) was performed using a multiparameter monitor (Cardell Touch, Midmark, USA). Intraoperative arterial oxygenation was monitored via arterial blood gas (ABG) analysis (ABL800 Basic, Radiometer, Denmark) (Table 1). Following CT the ETT was removed and the dog was bronchoscopically (OEV26IH 3.2mm flexible endoscope, Olympus, Australia) intubated with a left-DLT (Mallinckrodt 41F Left Broncho-Cath, Medtronic, Australia) as shown in Figure 1.

The bronchial port was placed into the right mainstem bronchus, as previously described by Adami et al. (2011). To check bronchial placement of the tube the bronchoscope was withdrawn from the bronchial tube lumen and placed into the tracheal tube lumen. The position of the bronchial tube was viewed, deemed to be correct, and the tracheal and bronchial tube cuffs inflated with air. The bronchial cuff was observed inflated at the entrance of the right mainstem bronchus. Anaesthesia was maintained with intravenous alfaxalone (Alfaxan-CD RTU, Jurox, Australia) boluses as required during this procedure.

A Y-piece attachment was placed between the DLT and semi-closed circle breathing system to allow either TLV or OLV. The dog was placed in right lateral recumbency for thoracoscopy, and the tracheal tube was occluded to initiate OLV of the right lung (dependent, non-surgical lung) through the bronchial tube. From that point, anaesthesia was maintained with isoflurane in oxygen (2 L/min). Rocuronium (Rocuronium Bromide Injection, Hospira Pty Ltd, Australia) at $0.25 \mathrm{mg} / \mathrm{kg}$ was administered intravenously to induce muscle paralysis and facilitate ventilation with a tidal volume of $260 \mathrm{~mL}$ creating a peak inspiratory pressure of $15 \mathrm{cmH}_{2} \mathrm{O}$. The minute volume was adjusted intraoperatively based on the dog's oxygenation $\left(\mathrm{PaO}_{2}, \mathrm{SpO}_{2}\right)$ and ventilation $\left(\mathrm{PaCO}_{2}, \mathrm{ETCO}_{2}\right)$ variables (Table 1). Eight-five minutes following initiation of OLV arterial oxygenation analysis showed a significant reduction (from $156 \mathrm{mmHg}$ to $85.2 \mathrm{mmHg}$ ). Changes to minute ventilation with multiple changes to both tidal volume and respiratory rate were made, however repeat $\mathrm{ABG}$ at 140 minutes showed arterial oxygenation had mildly declined further. At this point positive end expiratory pressure (PEEP) of $5 \mathrm{cmH}_{2} \mathrm{O}$ was applied, with use of a PEEP valve (PEEP Valve $5 \mathrm{cmH}_{2} \mathrm{O}$ MPN 4802, Boehringer, United States), to further assist intraoperative oxygenation by preventing the complete closure of alveoli during expiration (Lumb, 2017). 
An alveolar recruitment manoeuvre, providing an airway pressure of $30 \mathrm{cmH}_{2} \mathrm{O}$ for 30 seconds, was performed five minutes after applying PEEP in an attempt to recruit a proportion of collapsed alveoli. Sixty minutes after initiating OLV the dog became hypotensive (mean arterial pressure below $60 \mathrm{mmHg}$ ). Dopamine (DBL Dopamine, Hospira, Australia) was administered as a variable rate infusion (5-15 $\mathrm{ug} / \mathrm{kg} / \mathrm{min}$ ) to maintain normotension until the end of anaesthesia. Two-lung ventilation was reinstated after 195 minutes of OLV. At the end of surgery the dog was placed in sternal recumbency to assist with recovery from atelectasis. Nasal oxygen insufflation was provided until the dog had fully recovered.

\section{Case 2}

After 12 hours of fasting the dog was sedated intramuscularly with $0.009 \mathrm{mg} / \mathrm{kg}$ medetomidine (Domitor, Pfizer Animal Health, NSW Australia) and $0.3 \mathrm{mg} / \mathrm{kg}$ methadone. Forty-one minutes later, oxygen was administered via facemask (4 L/min) for five minutes. Anaesthesia was induced with $0.7 \mathrm{mg} / \mathrm{kg}$ alfaxalone and $0.7 \mathrm{mg} / \mathrm{kg}$ ketamine administered slowly intravenously to enable bronchoscopic intubation with a left DLT (Mallinckrodt 41F Left Broncho-Cath, Medtronic, Australia). An additional $10 \mathrm{mg}$ of alfaxalone was administered intravenously to facilitate positioning of the bronchial tube within the left mainstem bronchus. The DLT was marked at the level of the upper incisor for visual confirmation of any movement during the procedure. Correct tube placement was assessed as previously described for Case 1. Two-lung ventilation was initiated and anaesthesia maintained with isoflurane in oxygen $(2$ $\mathrm{L} / \mathrm{min}$ ), and fentanyl (5-10 ug/kg/hr) and ketamine (5$10 \mathrm{ug} / \mathrm{kg} / \mathrm{min}$ ) infusions. Vitals signs and arterial oxygenation were monitored as in Case 1 (Table 2). A CT performed immediately after intubation revealed incorrect placement of the DLT with excessive advancement and occlusion of the cranial branch of the left mainstem bronchus (Fig. 3). The DLT was then retracted and $\mathrm{CT}$ indicated correct placement of the bronchial port within the left mainstem bronchus without occlusion of any bronchial branches (Fig. 4).

The dog was moved to theatre and placed in left lateral recumbency for the surgery. An alveolar recruitment manoeuvre of three breaths (each of 10 seconds duration and $30 \mathrm{cmH}_{2} \mathrm{O}$ ) was performed manually. OLV consisted of a $270 \mathrm{~mL}$ tidal volume delivered in a volume-controlled mode (Merlin Small Animal Ventilator, Vetronic) that generated a peak inspiratory pressure of $15 \mathrm{cmH}_{2} \mathrm{O}$ to the left lung (by occlusion of the tracheal tube). Atracurium (Atracurium Besylate Injection, Hospira Pty Ltd, Australia) at $0.2 \mathrm{mg} / \mathrm{kg}$ was administered intravenously to facilitate mechanical ventilation. Minute volume was adjusted as in Case 1.
Arterial oxygenation remained above $222 \mathrm{mmHg}$ for the majority of the surgery with ABG taken 88 minutes after initiation of OLV showing a reduction to 81.5 $\mathrm{mmHg}$. Changes to minute ventilation showed no improvement in pulse oximetry values and after 108 minutes of OLV a second recruitment manoeuvre was performed followed by application of positive end expiratory pressure of $5 \mathrm{cmH}_{2} \mathrm{O}$ (Table 2). Repeat ABG showed a $\mathrm{PaO}_{2}$ of $282 \mathrm{mmHg}$. A third recruitment manoeuvre was performed prior to the reinstatement of TLV. At the end of surgery the dog was extubated and nasal oxygen insufflation provided until fully recovered.

\section{Discussion}

One-lung ventilation is an anaesthetic technique involving the iatrogenic collapse of one lung to facilitate surgical visualisation and access to that hemithorax. Hypoxemia is a significant risk secondary to introduction of a severe iatrogenic intrapulmonary shunt (Karzai and Schwarzkopf, 2009). When using a DLT to perform the technique, incorrect tube placement has the potential to increase this risk by unintentionally occluding additional areas of lung. The first dog presented here had lower arterial oxygenation than the second one and the authors speculate this difference might have been due to inappropriate DLT placement in the first dog with inadvertent collapse of the right cranial lung lobe.

The commercially available DLTs are designed for a human tracheal length of $9-15 \mathrm{~cm}$ (Robinson et al., 1998), while the average dog trachea is proportionally longer, wider and highly variable with the breed (Pascoe and Mayhew, 2015). The longer canine trachea means that DLTs can only be used in medium sized dogs. Canine maintstem bronchi are short, when compared to a human's, with the right mainstem bronchus often branching into the primary bronchi at the carina (and as such providing minimal length to accommodate the DLT bronchial port). The canine left mainstem bronchus is longer than the right and branches more caudally, nevertheless it is still considerably shorter than the human one (Pascoe and Mayhew, 2015). Therefore, a left sided DLT may obstruct the cranial bronchial branches of the left lung when used in a dog, as occurred in Case 2 when initially placed.

Examination of Case 1's original thoracic CT, performed four months prior as part of the diagnostic workup of laryngeal paralysis, indicated the right mainstem bronchus length to be $6 \mathrm{~mm}$ (Fig. 4). The DLT bronchial port distance from the end of the cuff to tip of the tube was $12 \mathrm{~mm}$ (Fig. 1). These measurements support the concern that the right mainstem bronchus of Case 1 was too short to accommodate the length of the left-sided DLT bronchial port. 
Table 1: Case 1 intraoperative ventilator settings and arterial blood gas results for each time point post intubation and post initiation of one-lung ventilation. S: spontaneous breathing, RR: respiratory rate, TV: tidal volume, PIP: peak inspiratory pressure, PEEP: positive end expiratory pressure, $\mathrm{ETCO}_{2}$ : end tidal carbon dioxide, $\mathrm{SpO}_{2}$ : peripheral capillary oxygenation saturation, $\mathrm{PaO}_{2}$ : partial pressure of oxygen in arterial blood, $\mathrm{PaCO}_{2}$ : partial pressure of carbon dioxide in arterial blood, MAP: mean arterial pressure.

\begin{tabular}{lccccc}
$\begin{array}{l}\text { Time point (minutes) (post DLT } \\
\text { intubation / OLV) }\end{array}$ & $10 / 10$ & $85 / 85$ & $115 / 115$ & $140 / 140$ & $250 / 250$ \\
\hline $\mathrm{RR}$ & 9 & 18 & 20 & 20 & 8 \\
$\mathrm{TV}(\mathrm{mL} / \mathrm{kg})$ & $\mathrm{S}$ & 9.4 & 9.4 & 9.4 & $\mathrm{~S}$ \\
$\mathrm{PIP}\left(\mathrm{cmH}_{2} \mathrm{O}\right)$ & $\mathrm{S}$ & 22 & 25 & 28 & $\mathrm{~S}$ \\
$\mathrm{PEEP}\left(\mathrm{cmH}_{2} \mathrm{O}\right)$ & - & - & - & 5 & - \\
$\mathrm{ETCO}_{2}(\mathrm{mmHg})$ & 52 & 45 & 51 & 48 & - \\
$\mathrm{SpO}_{2}$ & 100 & 91 & 90 & 91 & 93 \\
$\mathrm{PaO}_{2}(\mathrm{mmHg} / \mathrm{kPa})$ & $156 / 20.8$ & $85.2 / 11.4$ & $82 / 11$ & $78.6 / 10$ & $86.4 / 11.5$ \\
$\mathrm{PaCO}_{2}(\mathrm{mmHg} / \mathrm{kPa})$ & $49.6 / 6.6$ & $56.8 / 7.6$ & $51 / 6.8$ & $36.4 / 4.9$ & $38.5 / 5.1$ \\
$\mathrm{pH}$ & 7.2 & 7.1 & 7.1 & 7.2 & 7.3 \\
$\mathrm{MAP}(\mathrm{mmHg})$ & 85 & 65 & 75 & 75 & - \\
\hline
\end{tabular}

Table 2: Case 2 intraoperative ventilator settings and arterial blood gas results for each time point post intubation and post initiation of OLV. S: spontaneous breathing, NR: not recorded, RR: respiratory rate, TV: tidal volume, PIP: peak inspiratory pressure, PEEP: positive end expiratory pressure, ETCO2: end tidal carbon dioxide, $\mathrm{SpO} 2$ : peripheral capillary oxygenation saturation, $\mathrm{PaO} 2$ : partial pressure of oxygen in arterial blood, $\mathrm{PaCO}$ : partial pressure of carbon dioxide in arterial blood, MAP: mean arterial pressure.

\begin{tabular}{|c|c|c|c|c|c|c|c|c|c|}
\hline $\begin{array}{l}\text { Time point (minute) } \\
\text { (post DLT intubation / } \\
\text { OLV) }\end{array}$ & 24/TLV & 62/TLV & 92/TLV & $122 / 15$ & $147 / 40$ & $167 / 60$ & $195 / 88$ & $215 / 108$ & $\begin{array}{c}\text { 322/TLV } \\
\text { post-op }\end{array}$ \\
\hline $\mathrm{RR}$ & 7 & 9 & 14 & 14 & 18 & 18 & 16 & 14 & NR \\
\hline $\mathrm{TV}(\mathrm{mL} / \mathrm{kg})$ & $S$ & $S$ & 8 & 8 & 8.8 & 8.8 & 7.3 & 4.8 & - \\
\hline $\mathrm{PIP}\left(\mathrm{cmH}_{2} \mathrm{O}\right)$ & $S$ & $S$ & 15 & 15 & 16 & 16 & 17 & 14 & - \\
\hline $\operatorname{PEEP}\left(\mathrm{cmH}_{2} \mathrm{O}\right)$ & - & - & - & - & - & - & - & 5 & - \\
\hline $\mathrm{ETCO}_{2}(\mathrm{mmHg})$ & 58 & 58 & 51 & 46 & 39 & 38 & 41 & 66 & - \\
\hline $\mathrm{SpO}_{2}$ & 94 & 98 & 97 & 96 & 88 & 93 & 89 & 88 & 95 \\
\hline $\mathrm{PaO}_{2}(\mathrm{mmHg} / \mathrm{kPa})$ & $471 / 62.8$ & $470 / 62.7$ & $477 / 63.6$ & $225 / 30$ & $308 / 41$ & $227 / 30.3$ & $81.5 / 10.9$ & 282/37.6 & $228 / 30.4$ \\
\hline $\mathrm{PaCO}_{2}(\mathrm{mmHg} / \mathrm{kPa})$ & $55.7 / 7.4$ & $56.3 / 7.5$ & $49.3 / 6.6$ & $58.2 / 7.8$ & $47.6 / 6.3$ & $41.0 / 5.5$ & $54 / 7.2$ & $53.2 / 7.1$ & $46.4 / 6.2$ \\
\hline $\mathrm{pH}$ & 7.197 & 7.22 & 7.252 & 7.188 & 7.244 & 7.288 & 7.197 & 7.189 & 7.210 \\
\hline MAP (mmHg) & 85 & 95 & 65 & 65 & 65 & 75 & 70 & 75 & - \\
\hline
\end{tabular}

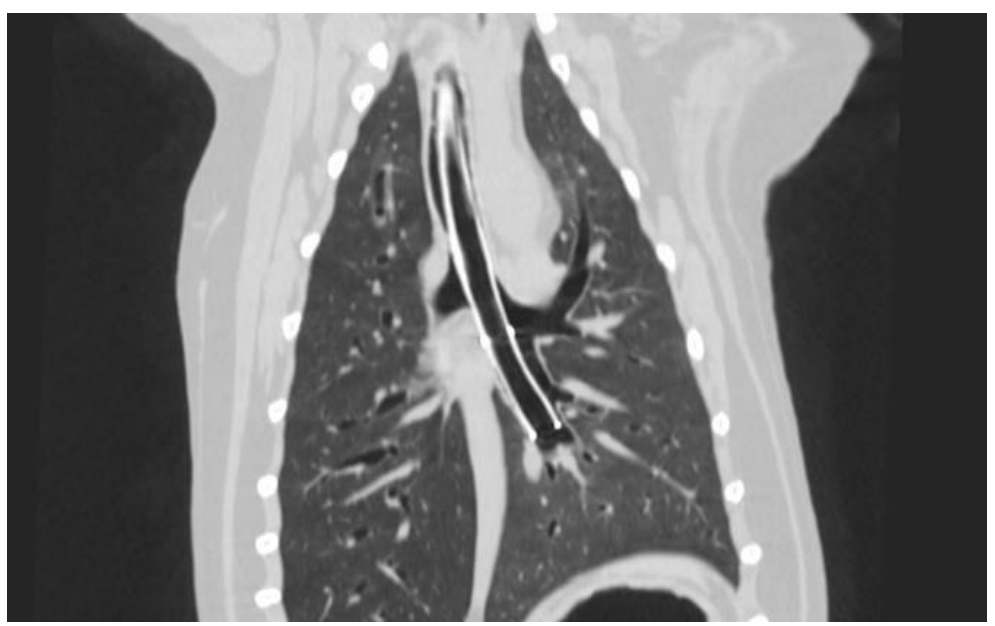

Fig. 3. CT of Case 2 showing excessive advancement of double-lumen tube into left mainstem bronchus, following bronchoscopic placement. 


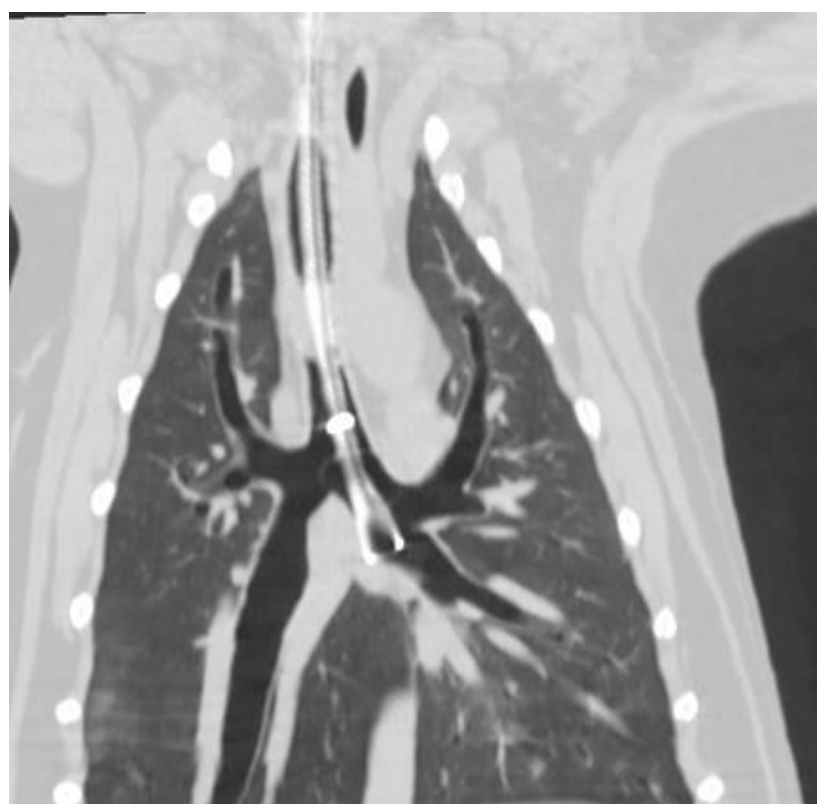

Fig. 4. CT of Case 2 showing correct placement of double-lumen tube within left mainstem bronchus, following retraction of tube $30 \mathrm{~mm}$.

An operator experienced in bronchoscopy placed the DLT in both cases presented. It is possible an operator with extensive experience specifically in the placement of DLT may have achieved correct placement. In human medicine DLT placement is the responsibility of the anaesthesiologist, with many different training programs in place to specifically provide them with this skill (Hagberg et al., 2003; Failor et al., 2014).

In Case 2, preoperative measurements comparing the dog's left mainstem bronchus to the DLT bronchial port were performed. The authors also elected to perform a CT to confirm the correct tube placement. Examination of the CT identified incorrect DLT placement, despite bronchoscopic placement, and allowed correct CT guided placement. Case 2 had markedly higher intraoperative $\mathrm{PaO}_{2}$ compared with Case 1 despite undergoing OLV of the smaller left lung (while Case 1 theoretically underwent OLV of the larger right lung), and having a longer anaesthetic time. The authors believe that, due to the probable increased iatrogenic shunting from right mainstem bronchus occlusion, Case 1 actually had 'half-lung ventilation' induced and as such the smaller ventilation field.

The placement of the DLT in Case 1 was unconventional as a left-sided DLT was introduced in the right mainstem bronchus. This modification was taken from the previously reported case of Adami et al. (2011). In that report, the authors noted one intraoperative arterial oxygen value of $135 \mathrm{mmHg}$ (ten minutes after starting OLV with delivery of isoflurane in only oxygen), and one post-operative value of 58 mmHg (15 minutes after extubation with the dog breathing room air). We believe it is likely that an unnoticed occlusion of the right cranial bronchus also occurred in this case and contributed to the low $\mathrm{PaO}_{2}$ reported.

Both veterinary (Pascoe and Mayhew, 2015) and human (Wiser, 2012) medical texts recommend bronchoscopic placement of DLT for OLV. Mayhew and Friedberg (2008) reported two cases using a DLT placed into the left mainstem bronchus to perform right OLV. The first dog had a reported arterial oxygenation of $315 \mathrm{mmHg}$ ten minutes after the introduction of OLV, while the second dog showed an arterial oxygenation of $73 \mathrm{mmHg}$ at the same time point. It is possible this significant difference in oxygenation was due to an incorrect placement of the DLT in the second dog. Mayhew et al. (2009) used a DLT in seven experimental dogs undergoing alternating OLV, with placement of the bronchial port into the left mainstem bronchus.

Placement of the DLT via bronchoscopy was problematic in four of the seven dogs, with two of these dogs having the DLT bronchial port accidentally placed into the right mainstem bronchus and another dog having accidental occlusion of the left cranial mainstem bronchial branches. Two of the three dogs had $\mathrm{PaO}_{2}$ of less than $80 \mathrm{mmHg}$, despite an inspired oxygen concentration of $100 \%$. As a rough estimation, the $\mathrm{PaO}_{2}$ should be approximately five times the inspired oxygen concentration in dogs without pulmonary disease (fraction of inspired oxygen to arterial partial pressure of ratio). During OLV a high fraction of inspired oxygen is necessary to prevention hypoxemia $\left(\mathrm{PaO}_{2}\right.$ less than $80 \mathrm{mmHg}$ ) due to the high pulmonary shunting (Lohser, 2008). Case 1, as well as some of the dogs 
reported by Mayhew et al. (2009), experienced $\mathrm{PaO}_{2}$ less than $80 \mathrm{mmHg}$ despite receiving $100 \%$ oxygen. This may indicate that the degree of shunting was greater than just one lung.

There are several other potential causes for the differences in the $\mathrm{PaO}_{2}$ seen between these two cases. The anaesthetic drugs used in each case did vary, however it is unlikely these differences alone could account for such significant differences in $\mathrm{PaO}_{2}$, as none of these anaesthetic drugs are reported to induce significant pulmonary dysfunction (Lohser, 2008). Case 1 received blood pressure support in the form of a dopamine infusion during the operative period when $\mathrm{PaO}_{2}$ decreased from $156 \mathrm{mmHg}$ to $85.2 \mathrm{mmHg}$ (54\% decline). Russel and James (2004) anaesthetised piglets with OLV and showed that the use of dopamine infusion resulted in mean arterial oxygenation reduction of $4.7 \%$, probably due to an increase in venous shunt fraction. Although dopamine may have contributed to the continued decline in $\mathrm{PaO}_{2}$ for Case 1 the authors consider it is unlikely this contribution would have been clinically significant to the overall $54 \%$ decline.

The same anaesthetist managed both cases. Given the difficulties experienced and the low arterial oxygenation that occurred for Case 1 , the anaesthetist managed Case 2 with a heightened appreciation of these challenges. Foremost a CT was performed to confirm correct placement of the DLT and application of recruitment manoeuvres were performed more often in Case 2. These manoeuvres aim to recruit atelectic alveoli with the application of a sustained inspiratory pressure, usually of 30 seconds duration. Case 1 had low arterial oxygenation from the beginning of surgery. The $\mathrm{PaO}_{2}$ was less than $90 \mathrm{mmHg}$ for over 55 minutes before a decision was made to introduce PEEP. Positive end expiratory pressure was introduced within five minutes of the first value below $200 \mathrm{mmHg}$ for Case 2 . It is possible that if these intervention measures had been undertaken earlier, Case 1 may have had overall better oxygenation.

Individual differences, including pulmonary function differences, could have accounted for differences in arterial oxygenation. One-lung ventilation was initiated at the time of DLT intubation for Case 1 with the first ABG taken ten minutes later, so unfortunately a preOLV $\mathrm{PaO}_{2}$ was not available. Preanaesthetic examination did not suggest any significant pulmonary disease in either case. Arterial oxygen partial pressure remained above $60 \mathrm{mmHg}$ in both cases and their packed cell volumes were within normal limits suggesting adequate oxygen carrying capacity. As such the clinical effect of the reduced arterial oxygenation seen is expected to be minimal, however this does highlight the potential for mild hypoxia when these techniques are used in dogs without pulmonary disease, and severe hypoxia in those with respiratory disease, anaemia or cardiovascular instability.

The use of CT guidance for DLT placement in Case 2 proved fundamental in preventing occlusion of the left cranial lung lobes. Current recommendations for DLT placement in dogs are via bronchoscopic guidance but, given the significant anatomical differences between humans and dogs, this alone may not be sufficient. Careful preoperative planning (measuring trachea, bronchi and DLT) was fundamental for correct case selection. Based on these cases, CT might be recommended as an aid to bronchoscopic DLT placement.

\section{Conflict of interest}

The Authors declare that there is no conflict of interest.

\section{References}

Adami, C., Axiak, S., Rytz, U. and Spadavecchia, C. 2011. Alternating one-lung ventilation using a double lumen endobronchial tube and providing CPAP to the non-ventilated lung in a dog. Vet. Anaesth. Analg. 38, 70-76.

Cantwell, S.L., Duke, T., Walsh, P.J., Remedios, A.M. and Walker, D. 2000. One-lung versus two-lung ventilation in the closed-chest anesthetized dog: a comparison of cardiopulmonary parameters. Vet. Surg. 29, 365-373.

Failor, E., Bowdle, A., Jelacic, S. and Togashi, K. 2014. High-fidelity simulation of lung isolation with double-lumen endotracheal tubes and bronchial blockers in anesthesiology resident training. J. Cardiothorac. Vasc. Anesth. 28, 865-869.

Flores, R.M., Park, B.J., Dycoco, J., Aronova, A., Hirth, Y., Rizk, N.P., Bains, M., Downey, R.J. and Rusch, V.W. 2009. Lobectomy by video-assisted thoracic surgery (VATS) versus thoracotomy for lung cancer. J. Thorac. Cardiovasc. Surg. 138(1), 11-18.

Fransson, B.A. 2015. History of small animal laparoscopy and thoracoscopy. In. Small Animal Laparoscopy and Thoracoscopy. Eds., Fransson, B.A., Mayhew, P.D. Iowa US: Wiley Blackwell Publishing, pp: xv-xvi.

Hagberg, C.A., Greger, J., Chelly, J.E. and Saad-Eddin, H.E. 2003. Instruction of airway management skills during anesthesiology residency training. J. Clin. Anesth. 15, 149-153.

Karzai, W. and Schwarzkopf, K. 2009. Hypoxemia during one-lung ventilation: prediction prevention, and treatment. Anesthesiology 110, 1402-1411.

Lansdowne, J.L., Monnet, E., Twedt, D.C. and Dernell, WS. 2005. Thoracoscopic lung lobectomy for treatment of lung tumors in dogs. Vet. Surg. 34, 530-535.

Lohser, J. 2008. Evidence-based management of onelung ventilation. Anesthesiology 26, 41-72. 
Lumb, A. 2017. Respiratory support and artificial ventilation. In: Nunn's Applied Respiratory Physiology. $8^{\text {th }}$ Edition. Italy. Elsevier, pp: 464-465.

Mayhew, P.D. and Friedberg, J.S. 2008. Video-assisted thorascopic resection of non-invasive thymomas using one-lung ventilation in two dogs. Vet. Surg. 37, 756-762.

Mayhew, K.N., Mayhew, P.D., Sorrell-Raschi, L. and Cimino Brown, D. 2009. Thoracoscopic subphrenic pericardectomy using double-lumen endobronchial intubation for alternating one-lung ventilation. Vet. Surg. 38, 961-966.

Mosley, C.A. 2015. Anesthesia Equipment. In: Veterinary Anesthesia and Analgesia. The Fifth Edition of Lumb and Jones. $5^{\text {th }}$ edition, Eds., Grimm, K.A., Lamont, L.A., Tranquilli, W.J. Iowa US. Wiley and Sons, pp: 27-28.

Pascoe, P.J. and Mayhew, P.D. 2015. Anesthesia for Thoracoscopy. In: Small Animal Laparoscopy and Thoracoscopy. Eds., Fransson, B.A. and Mayhew, P.D. Iowa US. Wiley Blackwell Publishing, pp: 255-270.
Robinson, C.L., Muller, N.L. and Essery, C. 1998. Clinical significance and measurement of the length of the right main bronchus. Can. J. Surg. 32, 27-28.

Russel, W.J. and James, M.F. 2004. The effects on arterial haemoglobin oxygen saturation and on shunt of increasing cardiac output with dopamine or dobutamine during one-lung ventilation. Anaesth. Intensive Care 35, 644-648.

Stankowski, T., Aboul-Hassan, S.S., Marczak, J., Szymanska, A., Augustyn, C. and Cichon, R. 2017. Minimally invasive thoracoscopic closure versus thoracotomy in children with patent ductus arteriosus. J. Surg. Res. 208, 1-9.

Walsh, P.J., Remedios, A.M., Ferguson, J.F., Cantwell, S. and Duke, T. 1999. Thoracoscopic Versus Open Partial Pericardectomy in Dogs: Comparison of Postoperative Pain and Morbidity. Vet. Surg. 28, 472-479.

Wiser, S. 2012. Technical aspects of lung isolation. In Practical Handbook of Thoracic Anesthesia, Ed., Hartigan, P.M. New York. Springer Science, pp: 141-158. 